\title{
EVALUATION OF THE POSSIBILITIES OF OCCURRENCE OF HARMFUL EFFECTS CAUSED BY SOME FERROALLOYS USED IN THE METALLURGICAL INDUSTRY ON THE ENVIRONMENT
}

\author{
Vasile BASTLIU \\ "Dunarea de Jos" University of Galati, Romania \\ e-mail: vbasliu@ugal.ro
}

\begin{abstract}
The raw materials of the metallurgical industry have an important chemical reactivity and when they come in contact with the environment, they can generate effects that in most cases are harmful. Chemical reactions from the solid / liquid interface showed a chemically active environment which caused the formation of reaction products with a certain degree of environmental damage.

The paper aimed to address the interaction between some coarse $(0.8 \mathrm{~mm})$ and fine $(0.04 \mathrm{~mm})$ ferro-alloys ( $\mathrm{FeSi}$ with $45 \% \mathrm{Si}$ ) with a physical simulation medium - distilled water for the possible determination of a change of $\mathrm{pH}$. For this purpose, chemical composition determinations were made by the EDX method and the morphological characterization of the surfaces by the SEM electron scanning method. Also, pH measurements were made on different granulations and quantities of FeSi45.
\end{abstract}

KEYWORDS: FeSi with $45 \% \mathrm{Si}, \mathrm{pH}$, aqueous extract, harmfulness, chemically active surfaces

\section{Introduction}

In general, the raw materials used in the metallurgical industry due to the quantities used and their intrinsic physico-chemical characteristics can cause harmful effects on the environment. A suggestive example of raw materials with harmful potential used in steelmaking processes can be given by the usual ferroalloys - FeSi45 in this case. They contain in addition to the main chemical elements $\mathrm{Fe}$ and $\mathrm{Si}$ and traces of other chemical elements such as: $\mathrm{Na}, \mathrm{K}, \mathrm{Al}, \mathrm{Ca}, \mathrm{Ni}, \mathrm{P}, \mathrm{S}$. resulting from the processes of elaboration of ferroalloys. Because the presence of these chemical elements in the industrial processes of obtaining ferroalloys are not specifically mentioned in international standards SR ISO 5445/1995 [1], they nonetheless feel their presence coming from the chemical composition of the raw materials that make them and are confirmed when chemical analysis is performed by EDX method in detail.

The paper aims to show that these chemical elements have direct effects on the environment. The impact on the environment is given by the fact that these raw materials are used in high quantities and their transport is done in bulk. Also, their storage is possible also by placing them directly on the ground in closed or open warehouses. Upon the contact of this with the water from the atmosphere (rain), they are washed and the water infiltrates the soil causing harmful effects on it in the sense of changing the physico-chemical character, in this case, the $\mathrm{pH}$ of rain or snow water, etc.

By the appearance of some changes in the $\mathrm{pH}$ of a physical simulation environment, that is, an aqueous extract consisting of distilled water and granular particles of FeSi45 with different dimensions, the degree of harmfulness of the chemical elements present on the active chemical surfaces of the ferroalloy particles. For this purpose, experiments were performed to form an aqueous extract consisting of distilled water $(50 \mathrm{~mL})$ with granular particles of FeSi45 ferroalloys with coarse $(0.8 \mathrm{~mm})$ and fine $(0.04 \mathrm{~mm})$ particle sizes.

\section{Materials and methods}

The determination of the changes of the chemical character of the environment by physical simulation was made by choosing a common dissolution medium - the fresh distilled water called and demineralized water because the impurities contained by the distillation process which involves 
the boiling (vaporization) were eliminated, and then by the condensation of the vapor obtained into a container followed by $\mathrm{pH}$ measurements.

We mention that there may be other methods of obtaining distilled water such as deionization and reverse osmosis [2].

Water, in general, has an amphoteric character that can be highlighted by the auto-protolytic reaction and thus it dissociates into $\mathrm{H}^{+}$and $\mathrm{OH}^{-}$ions $[5,6]$.

$\mathrm{H}^{+}$ions (or $\mathrm{H}_{3} \mathrm{O}^{+}$ions) give the aqueous solution an acidic character and $\mathrm{OH}^{-}$ions give the same aqueous solutions an alkaline character [6].

$$
\mathrm{H}_{2} \mathrm{O} \leftrightarrows \mathrm{H}_{(\mathrm{aq})}^{+}+\mathrm{OH}_{(\mathrm{aq})}^{-}
$$

One way to determine the acid-base character of aqueous solutions is to use the notion of $\mathrm{pH}$ [5]. Thus, Sorensen defines $\mathrm{pH}$ (hydrogen index) as the decimal logarithm (base 10) with changed sign (cologarithm) of hydrogen ion concentration. When water $\left(\mathrm{H}_{2} \mathrm{O}\right)$ interacts with other chemical elements, some of the chemical bonds in the water break down and new chemical bonds are formed, at the same time releasing hydrogen and the effect is to change the $\mathrm{pH}$ which can increase or decrease.

Literature $[4,7,8]$ mention among the first ways to obtain safe hydrogen gas at low temperatures the use of FeSi in the presence of an alkaline $\mathrm{NaOH}$ and water environment. This results in the decomposition of water and the release of hydrogen from the liquid state into the gaseous state according to the chemical reaction [9]:

$$
\mathrm{Si}+2 \mathrm{NaOH}+\mathrm{H}_{2} \mathrm{O} \leftrightarrows \mathrm{Na}_{2} \mathrm{SiO}_{3}+2 \mathrm{H}_{2}
$$

It is also possible to ambient temperature and the reaction [10]:

$$
\mathrm{Si}+2 \mathrm{H}_{2} \mathrm{O} \leftrightarrows \mathrm{SiO}_{2}+2 \mathrm{H}_{2}
$$

The direct effect is the $\mathrm{pH}$ shift of distilled water and this can be accounted for by the decomposition reaction of water and the release of $\mathrm{H}$ ions.
The second component is given by solid granular particles of FeSi45 with coarse $(0.8 \mathrm{~mm})$ and fine $(0.04 \mathrm{~mm})$ particle size fractions. For these, the morphology of the surface and the chemical composition were analyzed using the electron scanning electron microscope (SEM) equipped with an electronic probe (EDX) from Fei Quanta 200.

The measurements involved the introduction of granular particles into distilled water followed by mechanical stirring and $\mathrm{pH}$ measurements. To determine the $\mathrm{pH}$ of the aqueous extract we used a Hach Lange HQ40d multiparameter.

\section{Results and discussions}

The morphological analysis of the chemically active surface revealed a rough surface, often with defects that further enlarged the surface.

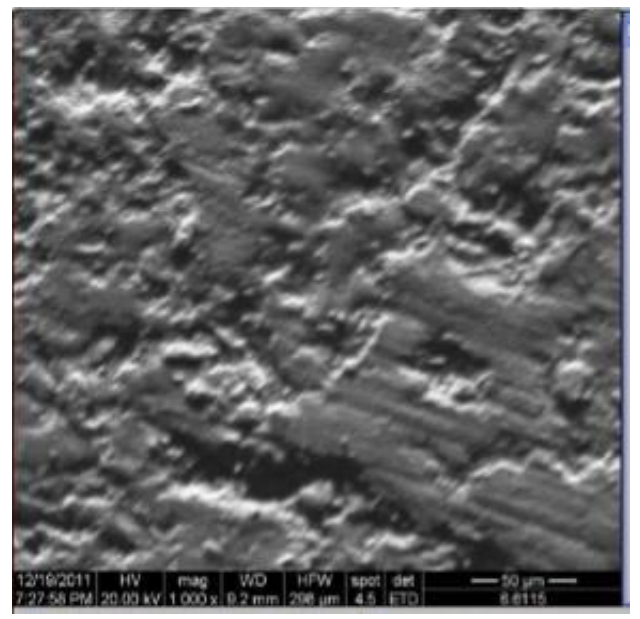

Fig. 1. Surface morphology of a granular particle of FeSi45 by SEM electron microscopy

[3]

It should also be mentioned that the FeSi45 ferroalloys have a rather high friable character which during the handling creates new active chemical surfaces by mechanical crushing, increasing the harmful effect even more.
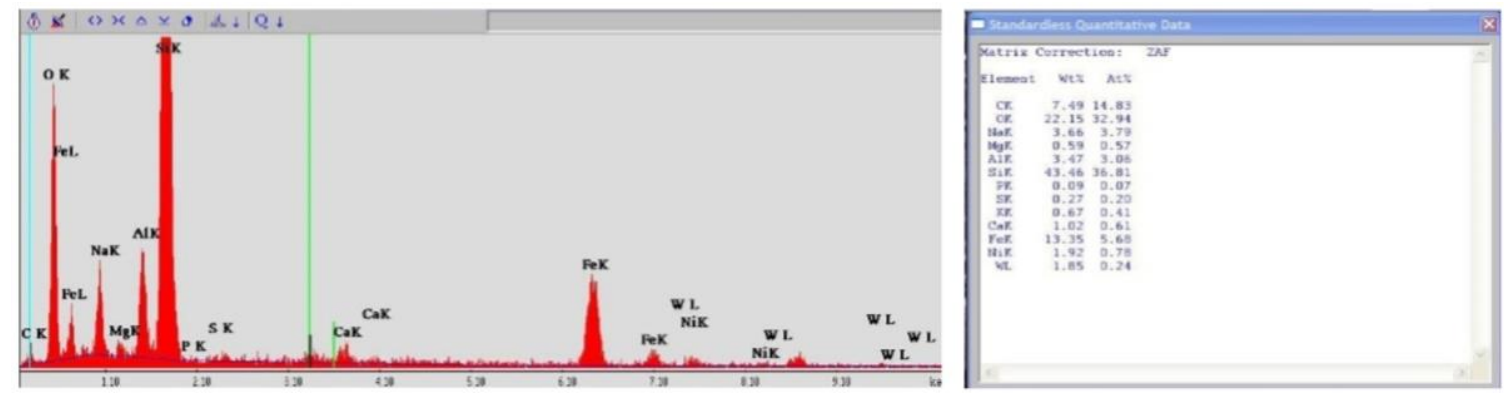

Fig. 2. Chemical analysis of a granular particle of FeSi45 with the help of the EDX probe 
The analyzed surface of the sample revealed the presence of active chemical elements in low concentrations of $\mathrm{Na}, \mathrm{K}, \mathrm{Al}, \mathrm{Ca}, \mathrm{Ni}, \mathrm{P}, \mathrm{S}$ at the trace level with a possible significant impact on the environment. The identification of these chemical elements suggests that at the contact with an aqueous environment the $\mathrm{pH}$ may swerve to the alkaline domain.

The high oxygen concentration can represent for us an indicator of the high reactivity of the surfaces with direct consequence in the formation of oxides.

Table 1. The values of the measured parameters of the aqueous extract consisting of FeSi45 with particle size $0.8 \mathrm{~mm}$ and $0.04 \mathrm{~mm}$

\begin{tabular}{|c|c|c|c|c|c|c|c|}
\hline \multirow{2}{*}{ No } & $\mathbf{2}$ & \multicolumn{3}{c|}{ Component } & \multicolumn{2}{|c|}{ Indicator } \\
\cline { 2 - 8 } & $\mathbf{A}$ & $\begin{array}{c}\text { Quantity } \\
{[\mathbf{m l}]}\end{array}$ & $\mathbf{B}$ & $\begin{array}{c}\text { Granulation } \\
{[\mathbf{m m}]}\end{array}$ & $\begin{array}{c}\text { Quantity } \\
{[\mathbf{g}]}\end{array}$ & $\mathbf{p H}$ & $\begin{array}{c}\text { Temperature } \\
{\left[{ }^{\circ} \mathbf{C}\right]}\end{array}$ \\
\hline A1 & Tap water & 50 & - & - & - & 7.71 & 23 \\
\hline A2 & Distilled water & 50 & - & - & - & 6.77 & 23 \\
\hline A3 & Distilled water & 50 & FeSi 45 & 0.8 & 0.5 & 9.05 & 23 \\
\hline A4 & Distilled water & 50 & FeSi 45 & 0.8 & 5 & 10.21 & 23 \\
\hline A5 & Distilled water & 50 & FeSi 45 & 0.8 & 50 & 10.92 & 23 \\
\hline A6 & Distilled water & 50 & FeSi 45 & 0.04 & 0.5 & 10.6 & 23 \\
\hline A7 & Distilled water & 50 & FeSi 45 & 0.04 & 5 & 10.85 & 23 \\
\hline A8 & Distilled water & 50 & FeSi 45 & 0.04 & 50 & 10.92 & 23 \\
\hline
\end{tabular}

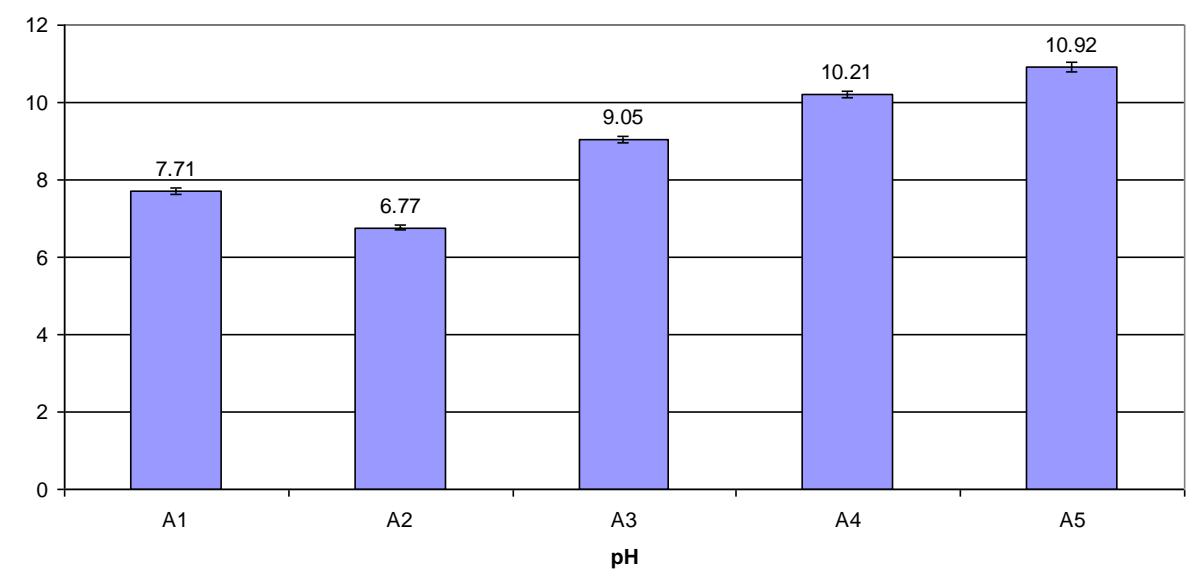

Fig. 3. $p H$ values for aqueous extract with granular particles of FeSi45 with $0.8 \mathrm{~mm}$

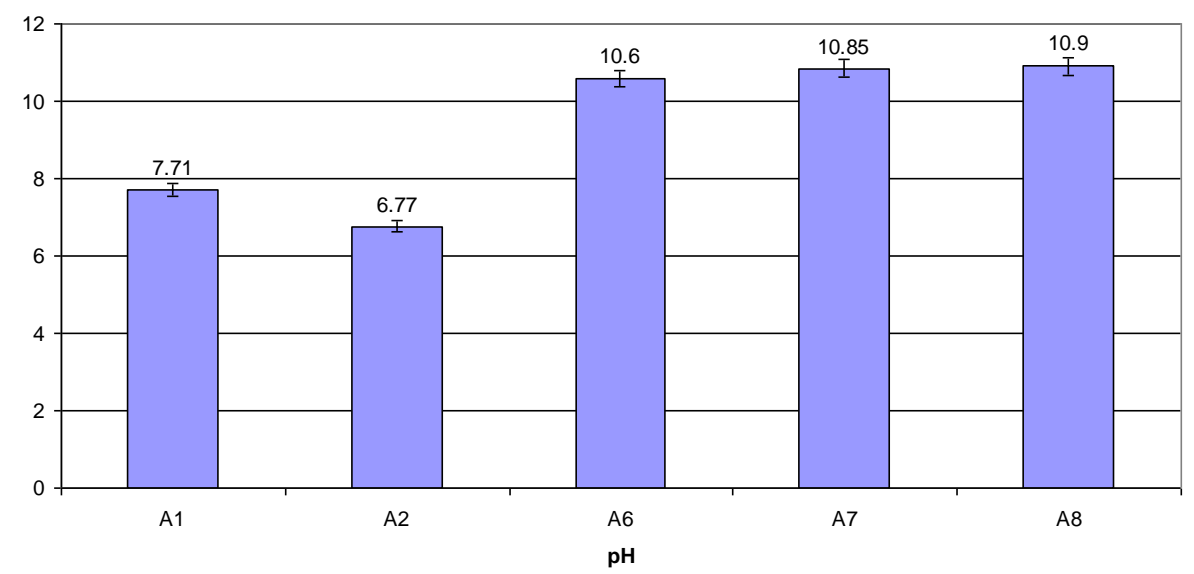

Fig. 4. $\mathrm{pH}$ values for aqueous extract with granular particles of $\mathrm{FeSi} 45$ with $0.04 \mathrm{~mm}$ 
The data shown in Figure 3 show an increase in $\mathrm{pH}$ values for the three concentrations $(0.5 \mathrm{~g}, 5 \mathrm{~g}$ and $50 \mathrm{~g}$ ) of FeSi45 introduced into distilled water as a result of their chemical reactivity. An increasing tendency of the $\mathrm{pH}$ can be observed suggesting that when the number of particles is higher and the concentration of transferred chemical elements in the distilled water is higher resulting an aqueous extract with $\mathrm{pH}$ in the alkaline domain.

In Figure 4 it can be observed an effect on the $\mathrm{pH}$ in the alkaline domain when we tested by the introduction of the granular particles of $0.04 \mathrm{~mm}$. It can be observed also, an increasing tendency when was increased the chemically active surface, and this is being able to be accounted by the chemical elements from their surfaces.

The results presented in Figures 3 and 4 show the formation of an aqueous extract with $\mathrm{pH}$ in the alkaline domain and thus an anionic rich water that can be used successfully in the industrial environment, a suggestive example being the emulsion of water in oil. The papers [11-13] show that water with $\mathrm{pH}$ in the alkaline domain stabilizes the emulsion of water in oil through an electrostatic stabilization mechanism.

\section{Conclusions}

The chemically active surfaces of the granular particles of FeSi45 with different granulations interacted with distilled water and they performed a chemical transfer of the constituents (Na, K, Al, Ca, $\mathrm{Ni}, \mathrm{P}, \mathrm{S}$ ions) changing the $\mathrm{pH}$ by turning it into alkaline domain.

The formation reaction of the aqueous extract took place at ambient temperature and we can suppose that also in the environment it can be favored the increase of the $\mathrm{pH}$.

By correlating the chemical composition with the $\mathrm{pH}$ of the aqueous extract we can assume that the conditions for the formation of basic oxides such as $\mathrm{NaOH}, \mathrm{KOH}$ and others have appeared.

It can be observed an increasing tendency by relating the quantity of granular particles to the amount of distilled water that we can put on account of the available chemically active surface. This can be observed in both situations for $0.8 \mathrm{~mm}$ and for 0.04 $\mathrm{mm}$.

Water with a $\mathrm{pH}$ in the alkaline domain can be used to stabilize oil emulsions in water.

It is desirable to use these ferroalloys for the purpose for which they were developed for the economic advantages they have.

The raw materials used in the metallurgical industry have a certain reactivity that requires attention because they can influence the quality of the environment.

\section{References}

[1]. ***, SR ISO 5445/1995.

[2]. ***, https://ro.wikipedia.org.

[3]. Bașliu V., Research regarding the obtaining of some technological utility composites with aluminum aloys base metal matrix and refractory particle, Doctoral thesis, "Dunarea de Jos" University of Galati, 2016.

[4]. Vacu S. Berceanu E., Niță P. S., Nicolae M., Metalurgia feroaliajelor, Editura Didactică și Pedagogică, București, 1980.

[5]. Benea L., Dima D., Chimie general, Laborator, Universitatea Dunărea de Jos din Galați, p. 11-15, 1997.

[6]. Negoiu D., Tratat de chimie anorganică, Editura Tehnică, p. 343, București, 1972.

[7]. Wlodek S., The reaction between $\mathrm{Si}^{+}$and $\mathrm{H}_{2} \mathrm{O}$. Interstellar implications, Mon. Not. R. astr. Soc., 242, p. 674-677, 1990.

[8]. Weaver E. R., Bery W. M., Bohnson V. L., Gordon B. D., The ferrosilicon process for the generation of hydrogen, 1920.

[9]. Brack P., Dann S. E., Upul Wijayantha K. G., Adcock P., Foster S., An old solution to a new problem? Hydrogen generation by the reaction of ferrosilicon with aqueous sodium hydroxide solutions, Energy Science and Engineering, 3(6), p. 535-540, doi: 10.1002/ese 3.94, 2015.

[10]. Kobayashi Y., Matsuda S., Imamura K., Kobayashi H., Hydrogen generation by reaction of Si nanopowder with neutral water, J Nanopart Res, 19, 176, DOI 10.1007/s11051-017-3873-z, 2017.

[11]. Oloro J., Effect of $p H$ and API Gravity on the Water-in-Oil Emulsion Stability, J. Appl. Sci. Environ. Manage., vol. 22, (6), p. 925-928, June 2018.

[12]. Alvarado V., Wang X., Moradi M., Review. Stability Proxies for Water-in-Oil Emulsions and Implications in Aqueousbased Enhanced Oil Recovery, Energies, 4, p. 1058-1086, doi:10.3390/en4071058, 2011.

[13]. Shulga G., Livcha S., Neiberte B., Verovkins A., Vitolina S., Zhilinska E., The effect of $\mathrm{pH}$ on the ability of different lignins to stabilize the oil-in-water emulsion, IOP Conf. Series: Materials Science and Engineering, 500, 012011, doi:10.1088/1757899X/500/1/012011, 2019. 